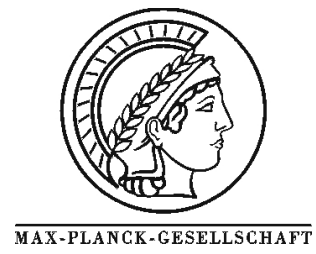

\title{
Interaction of ethylbenzene and styrene with iron oxide model catalyst films at low coverages: A NEXAFS study
}

\author{
Yvonne Joseph ${ }^{\text {a }}$, Mario Wühn ${ }^{\mathrm{b}}$, Arno Niklewski ${ }^{\mathrm{b}}$, Wolfgang Ranke*, , Werner Weiss ${ }^{\text {a }}$, \\ Christof Wöll ${ }^{\mathrm{b}}$, and Robert Schlögl ${ }^{\mathrm{a}}$
}

\author{
${ }^{a}$ Department of Inorganic Chemistry, Fritz-Haber-Institute of the MPG, Faradayweg 4-6, 14195 Berlin, \\ Germany \\ ${ }^{\mathrm{b}}$ Lehrstuhl für Physikalische Chemie I, Ruhr-Universität Bochum, 44780 Bochum, Germany \\ * Corresponding author: e-mail ressler@fhi-berlin.mpg.de, phone +49 308413 4523, fax +4930 84134401 \\ Submitted 03rd August 2000; accepted 14 September 2000
}

\begin{abstract}
The adsorption of ethylbenzene and styrene on well ordered epitaxial iron oxide model catalyst films with different stoichiometries was investigated using near edge X-ray absorption fine structure spectroscopy (NEXAFS). On the iron-terminated $\mathrm{Fe}_{3} \mathrm{O}_{4}(111)$ and $\alpha-\mathrm{Fe}_{2} \mathrm{O}_{3}(0001)$ surfaces a chemisorption of ethylbenzene and styrene is observed which initially occurs on the iron sites via the $\pi$-electron system of the phenyl ring. This forces the molecules into an almost flat lying configuration ( $\eta^{6}$ like ring adsorption geometry). In the case of ethylbenzene this adsorption complex is supposed to lead to an activation of the $\mathrm{C}-\mathrm{H}$ bonds thus facilitating the dehydrogenation to styrene. The tilt angle of the aromatic ring systems increase to about $40^{\circ}$ when approaching monolayer saturation. In contrast, the interaction with the oxygen-terminated $\mathrm{FeO}(111)$ surface is weak and of the physisorption type. The adsorbate-adsorbate interaction dominates and causes a tilted adsorption of the molecules from the beginning.
\end{abstract}

\section{Introduction}

Iron oxides are industrially used as catalysts for the water gas shift reaction, the styrene synthesis from ethylbenzene and in the removal of hydrogen sulfide from reducing gas mixtures[1]. As for many other important heterogenous catalysts very little is known about structure-reactivity relationships and on the reaction mechanism on an atomic scale. Yet, both the understanding of the molecular processes during the reaction and information about the nature of the active sites are essential for catalyst development or optimisation.

The dehydrogenation of ethylbenzene (EB) to styrene (St) over iron oxide based catalysts is carried out in a mixture of EB and steam (1:5) at temperatures around $900 \mathrm{~K}[2-4]$. For this reaction detailed investigations were carried out. Not only real industrial catalysts have been investigated[5-7], also surface science studies of iron oxide model catalyst films were performed in ultrahigh vacuum (UHV) and combined with reaction experiments[8-10]. These single crystalline iron oxide films were grown epitaxially on a $\mathrm{Pt}(111)$ substrate by iron evaporation and subsequent oxidation[11, 12]. Depending on the amount of evaporated iron, the oxygen partial pressure, the temperature and duration of the oxidation the films show a well defined $\mathrm{FeO}(111)$ (wustite), $\mathrm{Fe}_{3} \mathrm{O}_{4}(111)$ (magnetite) or $\alpha-\mathrm{Fe}_{2} \mathrm{O}_{3}(0001)$ (hematite) structure and stoichiometry as revealed by photoelectron spectroscopy (UPS/XPS) and x-ray absorption spectroscopy (NEXAFS)[13]. The surface structures of the oxide films are known from low energy electron diffraction (LEED) and scanning tunneling microscopy (STM): While the $\mathrm{FeO}(111)[14]$ film is oxygen terminated, the surfaces of the $\mathrm{Fe}_{3} \mathrm{O}_{4}(111)[15]$ film is terminated by a hexagonal oxygen layer covered by $1 / 4$ monolayer of iron cations. The surface termination of the $\alpha-\mathrm{Fe}_{2} \mathrm{O}_{3}(0001)[16]$ film is still under discussion, but there is evidence that an oxidation at low oxygen pressures $\left(\leq 10^{-4} \mathrm{mbar}\right)$ results in a partial iron termination on a hexagonal oxygen layer. All three surfaces are strongly relaxed[17]. Models of the surface structures and the corresponding LEED patterns of the iron oxide films are shown in fig. 1.

The adsorption behavior of EB, St and water can be understood in terms of the acid - base properties of the surface. The FeO film exposes only basic oxygen sites whereas the iron cations on the $\mathrm{Fe}_{3} \mathrm{O}_{4}$ and $\mathrm{Fe}_{2} \mathrm{O}_{3}$ films have Lewis acidic character. Compared to $\mathrm{Fe}_{3} \mathrm{O}_{4}$ the acid character of the $\mathrm{Fe}_{2} \mathrm{O}_{3}$ surface is harder because it does not contain $\mathrm{Fe}^{2+}$ ions. The chemical interaction of the soft bases $\mathrm{EB}$ and $\mathrm{St}$ is expected to be stronger with the softer acidic $\mathrm{Fe}_{3} \mathrm{O}_{4}$ surface and weaker 
with the $\mathrm{Fe}_{2} \mathrm{O}_{3}$ surface. No chemical interaction should occur with the basic $\mathrm{FeO}$ surface. Indeed the chemical behaviour of these films investigated by adsorption and desorption of ethylbenzene[9,18,19], styrene[10] and water[20-22] reveal no chemisorbed states on the oxygen terminated $\mathrm{FeO}(111)$ surface whereas on the partly iron terminated surfaces $\mathrm{Fe}_{3} \mathrm{O}_{4}(111)$ and $\alpha-\mathrm{Fe}_{2} \mathrm{O}_{3}(0001)$ a chemisorbed state has been observed for all three adsorbates. The calculated heats of adsorption[19] and desorption energies[22] indicate a stronger interaction of the aromatic molecules with $\mathrm{Fe}_{3} \mathrm{O}_{4}\left(\mathrm{e} . \mathrm{g} . \mathrm{E}_{\mathrm{des}}(\mathrm{EB})=86 \mathrm{~kJ} / \mathrm{mol}\right)$ than with $\mathrm{Fe}_{2} \mathrm{O}_{3}$ (e. g. $\mathrm{E}_{\text {des }}(\mathrm{EB})=64 \mathrm{~kJ} / \mathrm{mol}$ ). Furthermore these adsorption studies give strong evidence that the top layer iron cations are the active sites for chemisorption.

In order to demonstrate the relevance of these model catalysts for the dehydrogenation of ethylbenzene, the UHV studies were combined with reaction experiments under pressure and temperature conditions near to the real catalytic process. Batch reactor experiments reveal that $\mathrm{FeO}(111)$ and $\mathrm{Fe}_{3} \mathrm{O}_{4}(111)$ are catalytically inactive wheras on $\alpha-\mathrm{Fe}_{2} \mathrm{O}_{3}$ a conversion is observed[8]. With increasing defect density on the surface, as qualitatively estimated from LEED patterns, the reaction rate increases. Therefore defects were proposed to be the active sites for dehydrogenation. Flow reactor experiments combined with surface science methods show similar results and the reaction mechanism shown in fig. 2 has been proposed[23]. The educt molecules (EB) adsorb on the oxide surface by interaction of the aromatic ring with the iron cations (1). This specific adsorption leads to an activation of the $\mathrm{C}-\mathrm{H}$ bonds in the side chain. Then, the dehydrogenation occurs at a defect nearby which may either be a step (as illustrated in fig. 2), an adatom or vacancy exposing coordinatively unsaturated oxygen. These Brønsted basic oxygen sites may deprotonate two C-H groups of the ethyl group (2). The desorption of the product molecules (St) follows and the surface is left with the hydrogen atoms on the oxygen containing defect site thus forming hydroxyl groups and reduced iron species (3). The catalytic cycle gets formally completed by desorption of hydrogen and reoxidation of the iron (4). A desorption of water instead of hydrogen and reoxidation of the oxygen vacancy by water from the gas phase in this last step (oxidehydrogenation) cannot be ruled out.

This mechanism implies, that ethylbenzene and styrene interact mainly with their $\pi$-orbitals. In order to reveal their adsorption geometry, we present a near-edge $\mathrm{x}$-ray absorption fine structure spectroscopy (NEXAFS) study of the adsorption of ethylbenzene and styrene on the three model catalyst films. The study focusses on low EB and St coverages because an extrapolation of TDS data to reaction conditions using the Langmuir isotherm[22] has indicated that under reaction conditions only the chemisorbed states are occupied and even they only partly. Note that the competitive adsorption of the molecules has not been studied by NEXAFS, because there are indications from coadsorption TDS measurements that all three adsorbates compete for the same substrate sites, and because the spectra of ethylbenzene and styrene are too similar to distinguish them, when overlapping.

\section{Experimental}

All experiments were carried out in an UHV chamber with a base pressure below $5 \times 10^{-10} \mathrm{mbar}$ at the beamline HETGM-2 at BESSY I in Berlin with a resolution $\mathrm{E} / \Delta \mathrm{E}=580[24]$. The chamber was equipped with a sputter gun for ion

bombardment $\left(\mathrm{Ar}^{+}\right)$, an iron evaporator, a LEED unit, a twin anode X-ray source and a CLAM2 energy analyzer (Vacuum Generators), a home made NEXAFS partial yield electron detector based on a double channel plate (Galileo), a quadrupole mass spectrometer (Pfeiffer) and dosing lines for argon, oxygen and the organic molecules. EB and St were degassed by several pump-freeze-thaw cycles, exposure occurred by backfilling the chamber via a leak valve. The purity of all gases was checked by mass spectrometry. The ionization gauge reading for EB and St was corrected by the factor 1/7 in order to account for the higher ionisation probability of the aromatic molecules compared to nitrogen[25]. The sample could be heated up to $1300 \mathrm{~K}$ by electron bombardment and cooled down to $120 \mathrm{~K}$ using liquid nitrogen while the temperature was controlled via a Ni-NiCr thermocouple.

After cleaning the $\mathrm{Pt}(111)$ substrate by sputter-anneal and oxidation cycles, the $\mathrm{FeO}(111)$ and $\mathrm{Fe}_{3} \mathrm{O}_{4}(111)$ surfaces were prepared by iron deposition and subsequent oxidation as described before[18]. The $\mathrm{Fe}_{2} \mathrm{O}_{3}(0001)$ surface was formed from $\mathrm{Fe}_{3} \mathrm{O}_{4}(111)$ by oxidation for 30 minutes at $870 \mathrm{~K}$ in $1 \times 10^{-4}$ mbar $\mathrm{O}_{2}$. The clean surfaces $\left[\mathrm{Pt}(111), \mathrm{FeO}(111), \mathrm{Fe}_{3} \mathrm{O}_{4}(111)\right.$ and $\mathrm{Fe}_{2} \mathrm{O}_{3}(0001)$ ] were characterized by XPS, NEXAFS and LEED to check their stoichometry, cleanliness and surface order.

In the adsorption experiments different amounts of EB and St were deposited on the iron oxide films. From previous desorption measurements $[10,18]$ the temperatures are known where the surfaces are covered with the first layer species only (chemisorbed species on $\mathrm{Fe}_{3} \mathrm{O}_{4}$ and $\mathrm{Fe}_{2} \mathrm{O}_{3}$ and physisorbed species on $\mathrm{FeO}$ ). At these temperatures, the surfaces were exposed to small amounts of the aromatic molecules in order to obtain partial coverages. First layer saturation coverages were obtained by further exposure. The applied temperatures and exposures are given in the figs. 4-6. In all cases the sample was cooled down after deposition to prevent desorption. A small additional adsorption from the residual gas could not be avoided completely. The condensed (multi)layers used as reference were prepared below condensation temperature using large exposures (20L). Reference data have also been recorded for multilayers of benzene and octane.

From the clean surfaces and from all adsorbate covered layers, C 1s XP spectra were taken in order to determine the coverage. The intensity for saturation of the first layer in the respective adsorbate-substrate system was assigned to 1 monolayer (ML) and the submonolayer coverages determined according to their $\mathrm{C} 1 \mathrm{~s}$ peak intensities. The $\mathrm{C} \mathrm{K}$-edge NEXAFS spectra were recorded at normal $\left(90^{\circ}\right)$ and grazing $\left(30^{\circ}\right)$ X-ray incidence applying a retarding voltage of $-150 \mathrm{~V}$ (partial electron yield, PEY-mode) in order to enhance the surface sensitivity by reducing contributions from inelastically scattered electrons. For nearly all layers, spectra were also taken for a third angle of incidence $\left(55^{\circ}\right)$, but they will not be shown to make the presentation clearer. After correcting the exact energy position of the monochromator the spectra from the corresponding clean iron oxide surfaces were subtracted from the raw data to remove substrate signals. The spectra were then normalized to constant photon flux over the spectral range by dividing by a spectrum recorded from a freshly sputtered $\mathrm{Au}$ 
wafer. In all NEXAFS spectra shown here, intensities are normalized in units of the carbon edge adsorption step height (difference in intensity between $280 \mathrm{eV}$ and $325 \mathrm{eV}$ ). In order to compare the intensities, the $\pi^{*}$ resonances were fitted by gaussian shaped lines of the same linewidth. The ratio of these intensities was used to estimate the tilt angle $\alpha$ by applying Fermis rule. Here the resonance intensity is proportional to $\cos ^{2} \alpha$, which is deduced by simple geometric arguments [26]. The uncertainities in this evaluation method results in an error of 2 degrees. Most of the spectra give average values because a number of scans are summed up. As it will be discussed in detail, the actual tilt angle of the molecular plane with respect to the surface may deviate from the evaluated one.

\section{Results}

Fig. 3 compares the spectra of condensed EB, St, benzene and octane. In the spectrum of condensed EB and St the spectral features A', A-E are marked. Their assignment given in table 1 is based on corresponding data for benzene and octane[27, 28]. The spectra of EB and St are similar to the spectrum of benzene. The resonance A is slightly broader for EB and St than for benzene. The styrene resonance has a low energy shoulder ( $\left.\mathrm{A}^{\prime}\right)$. The Rydberg resonance B has a slightly higher intensity for EB and St due to additional contributions from the side chain carbon atoms. The spectra of the condensed phases were also measured at normal and glancing incidence (not shown) but they are almost independent of the incidence angle indicating an average tilt angle of $54^{\circ}$, which is also consistent with a random orientation[26].

Fig. 4 presents carbon K edge NEXAFS spectra for low EB coverages on $\mathrm{FeO}(111), \mathrm{Fe}_{3} \mathrm{O}_{4}(111)$ and $\alpha-\mathrm{Fe}_{2} \mathrm{O}_{3}(0001)$ and compares them to the multilayer spectrum. All energetic positions of the resonances agree with those of the condensed phase. The first $\pi^{*}$ resonance (A) of condensed EB is narrow (FWHM $=0.7 \mathrm{eV}$ ). For small coverages on $\mathrm{Fe}_{3} \mathrm{O}_{4}(111)$ and $\alpha$ $\mathrm{Fe}_{2} \mathrm{O}_{3}(0001)$ it is broadened considerably $(\mathrm{FWHM}=1.2 \mathrm{eV})$ whereas on $\mathrm{FeO}(111)$ the broadening is small $(\mathrm{FWHM}=0.9$ $\mathrm{eV})$. The $\pi^{*}$ resonances exhibit a strong dichroism with a higher intensity for grazing incidence. Assuming undisturbed electronic structure of the adsorbates, the tilt angle between the plane of the phenyl ring and the surface (or between the direction of the dipole transition moment and the surface normal) can be calculated. This analysis yields tilt angles of $39 \pm 2^{\circ}$ in the case of $\mathrm{FeO}(111), 7^{\circ} \pm 2^{\circ}$ on the $\mathrm{Fe}_{3} \mathrm{O}_{4}(111)$ and $21^{\circ} \pm 2^{\circ}$ on the $\alpha-\mathrm{Fe}_{2} \mathrm{O}_{3}(0001)$ surface. The $\sigma^{*}$ resonances $(\mathrm{D}, \mathrm{E})$ show the inverse intensity behaviour as expected from theory[26]

Upon monolayer saturation the tilt angles both for EB and St increase to values around $40^{\circ}$. As an example, fig. 5 shows the corresponding data for $\mathrm{EB}$ adsorbed on $\mathrm{Fe}_{3} \mathrm{O}_{4}$.

Fig. 6 compares low coverage NEXAFS spectra recorded for styrene adsorbed on the three oxide films with the styrene multilayer spectrum. Also here the low coverage spectra exhibit a strong dichroism. Similar to EB, the styrene molecules chemisorbed at partial coverage on $\mathrm{Fe}_{3} \mathrm{O}_{4}$ and $\mathrm{Fe}_{2} \mathrm{O}_{3}$ are tilted less $\left(23^{\circ}-28^{\circ}\right)$ with respect to the surface than the species physisorbed on $\mathrm{FeO}(111)\left(\sim 43^{\circ}\right)$. As for $\mathrm{EB}$ the tilt angle increases when approaching saturation coverage of the chemisorbed species. Also here the first $\pi *$ resonance on $\mathrm{Fe}_{3} \mathrm{O}_{4}(111)$ and $\alpha-\mathrm{Fe}_{2} \mathrm{O}_{3}(0001)$ is broadened (in both cases $\mathrm{FWHM}=1.1 \mathrm{eV}$ ) compared to adsorption on $\mathrm{FeO}(111)$ and to the condensed phase (for both $\mathrm{FWHM}=0.8 \mathrm{eV}$ ).

\section{Discussion}

The differences in the NEXAFS spectra of the condensed phases of EB and St (fig.3) can be explained by the different structure of the molecules. The slightly broader resonance (A) of EB and St compared to benzene is assigned to symmetry breaking caused by the side chains [e. g. $D_{6 h}$ (benzene) $\rightarrow C_{s}$ (planar styrene)] resulting in different excitation energies for the non-equivalent carbon atoms as demonstrated previously for phenole and aniline on $\operatorname{Ag}(111)$ [29]. The shoulder of the first resonance $\left(\mathrm{A}^{\prime}\right)$ can be assigned to the additional $\pi$ system of the vinyl group in St compared to EB as shown by ab-initio calculations[30]. A corresponding feature exists also in the NEXAFS spectrum of polyphenylacetylen[31] (repeat unit similar to styrene: $-\mathrm{C}(\mathrm{ph})=\mathrm{CH}-, \mathrm{ph}=$ phenyl) whereas it is absent in polystyrene[32] (repeat unit similar to ethylbenzene: $-\mathrm{CH}(\mathrm{ph})-$ $\mathrm{CH}_{2^{-}}, \mathrm{ph}=$ phenyl ). Also gas phase measurements [33] of ethylbenzene, styrene and benzene show this difference.

In agreement with previous reported adsorption studies[18] the present NEXAFS study reveals no chemical interaction of EB or St with the oxygen terminated FeO(111) surface. The adsorption temperatures are below $200 \mathrm{~K}$ and the FWHM of the first $\pi^{*}$ resonance is small. This absence of a chemisorbed species is due to a repulsive electrostatic interaction between the surface oxygen atoms and the $\pi$ orbitals or, in the acid-base picture, to the basic character of both surface and adsorbate. The adsorbate-adsorbate interaction here exceeds the adsorbate-substrate interaction and causes the typically observed tilt angles of about $40^{\circ}$. Probably the physisorbed layer grows immediately in form of two-dimensional islands.

For the iron terminated $\mathrm{Fe}_{3} \mathrm{O}_{4}$ and $\mathrm{Fe}_{2} \mathrm{O}_{3}$ surfaces chemisorbed species are observed as shown by the higher adsorption temperature and the broadening of the $\pi^{*}$ resonances in the NEXAFS spectra. This is also in line with former results[10, 18]. Because of the absence of a chemisorbed species on the purely oxygen terminated $\mathrm{FeO}(111)$ surface it can be concluded that the soft basic aromatic molecules EB and St chemisorb on the acidic iron sites of the $\mathrm{Fe}_{3} \mathrm{O}_{4}$ and $\mathrm{Fe}_{2} \mathrm{O}_{3}$ surfaces. An interaction of the highest occupied molecular $\pi$ orbital (HOMO) of the aromatic molecules with the unoccupied iron $3 \mathrm{~d}$ states has to be assumed. This agrees with UPS measurements of $\mathrm{EB}$ on $\mathrm{Fe}_{3} \mathrm{O}_{4}(111)$, where a shift and splitting of the HOMO was observed[18]. The broadening of the first $\pi^{*}$ resonance(A) in the NEXAFS spectra indicates that also the lowest unoccupied molecular orbitals (LUMO, $\pi^{*}$ ) of EB and St interact with the occupied iron $3 \mathrm{~d}$ states of the $\mathrm{Fe}_{3} \mathrm{O}_{4}(111)$ and $\alpha-\mathrm{Fe}_{2} \mathrm{O}_{3}(0001)$ surfaces. In analogy to models developed to describe the bonding of $\pi$ ligands in complex chemistry[34], this metal adsorbate interaction can be described with two different binding models. In the Dewar-Chatt-Duncanson model a donation of electrons from the $\pi$-HOMO of the ligand into unoccupied metal $d$ orbitals and simultaniously backdonation of electron density from the occupied metal $\mathrm{d}$ orbitals into the $\pi^{*}$-LUMO is assumed. The planar aromatic ring is regarded as a monodentate ligand 
containing only $\mathrm{sp}^{2}$-hybridized carbon atoms. Alternatively, the ring is regarded as a hexadentate ligand with six metal carbon bonds. The character of the carbon hybrid orbitals approaches an $\mathrm{sp}^{3}$ configuration and therefore the hydrogen atoms are bent out of the ring plane which is generally observed for the interaction of $\pi$-systems with metals. For both models the bonds within the molecule become weaker. The real binding situation is proposed to be inbetween these two models resulting in an $\eta^{6}$-like complex of the aromatic ring of EB or St. Indeed, the dichroism of the NEXAFS spectra and the broadening of the $\pi^{*}$ resonance which we have observed is consistent with such a flat adsorption geometry at low surface coverages.

The evaluated tilt angle values, however, should rather be regarded as qualitative. Several reasons may be responsible for a non-zero intensity observed under normal incidence. Not only the surface roughness of the oxide substrate or the averaging over a large number of molecules adsorbed on different domains may contribute to this intensity, also the interaction of the side chain with the surface, although probably weak, may cause a tilt of the phenyl group out of a perfectly flat configuration. The surface coverage is also important. We observe an increase of the tilt angle with coverage (see fig. 5). We ascribe this to the increasing intermolecular interaction between adsorbate molecules which leads to a tilted configuration when it dominates over the adsorbate-substrate interaction. For the weak physisorption of $\mathrm{EB}$ or $\mathrm{St}$ on $\mathrm{FeO}(111)$, the adsorbate-adsorbate interaction dominates always resulting in a tilted layer even for small coverages. It is known that the interaction of the ring during adsorption may lead to $\mathrm{C}-\mathrm{H}$ bonds bent out of the plane[27] as described by the second complex model described above. Also this would cause a small intensity under normal incidence[35]. This suggests that the molecules not only adsorb on the iron cations on the suface in a $\eta^{6}$ like geometry but that this interaction also activates all C-H bonds (in the side chain as well) which is important for the hydrogen transfer to the basic sites of the surface during dehydrogenation. A C-H bond activation in the side chain due to an interaction of EB with an iron-oxygen cation is also known from gas phase investigations[36, 37]. These findings agree well with the mechanism for the EB dehydrogenation proposed by Kuhrs et al.[23] as shown in fig. 2 .

Qualitatively, the chemisorption behaviour of ethylbenzene and styrene on $\mathrm{Fe}_{3} \mathrm{O}_{4}(111)$ and $\mathrm{Fe}_{2} \mathrm{O}_{3}(0001)$ is similar, whereas no chemisorption is found on $\mathrm{FeO}(111)$. This lack of a chemisorbed state explains why the $\mathrm{FeO}(111)$ surface is catalytically inactive. The fact that also $\mathrm{Fe}_{3} \mathrm{O}_{4}$ is inert towards the dehydrogenation of ethylbenzene could be due to the higher surface coverage under reaction conditions. It was estimated[22] that the coverage by chemisorbed EB and St under reaction conditions is about $35 \%$ on $\mathrm{Fe}_{2} \mathrm{O}_{3}$ whereas the reaction product $\mathrm{St}$ occupies all sites on $\mathrm{Fe}_{3} \mathrm{O}_{4}$ due to its stronger interaction. The missing catalytic activity of $\mathrm{Fe}_{3} \mathrm{O}_{4}$ is explained by site blocking by the product molecules[4]. Our results reveal that the $\eta^{6}$-like interaction of the aromatic ring exists only for coverages clearly below saturation of the chemisorbed species. It seems thus possible that site blocking is not the only reason for the missing activity of $\mathrm{Fe}_{3} \mathrm{O}_{4}$ but that also the tilted adsorption configuration of the educt molecule EB due to its high coverage prevents its dehydrogenation. This is schematically depicted in fig. 7 .

\section{Summary and conclusions}

At low coverage the chemisorption of $\mathrm{EB}$ and $\mathrm{St}$ on $\mathrm{Fe}_{3} \mathrm{O}_{4}(111)$ and $\alpha-\mathrm{Fe}_{2} \mathrm{O}_{3}(0001)$ occurs via the $\pi$-system of the phenyl ring and forces the molecules into an almost flat lying $\eta^{6}$-like adsorption configuration. This configuration may also lead to an activation of the $\mathrm{C}-\mathrm{H}$ bonds of $\mathrm{EB}$ by deforming the aromatic ring. This could facilatate the catalytic dehydrogenation of EB.

When the coverage of the chemisorbed species approach saturation, the growing adsorbate-adsorbate interaction causes the tilt angle to increase to about $40^{\circ}$ and a $\mathrm{C}-\mathrm{H}$ bond activation is no more expected. This suggests that catalytic activity is only to be expected for partial coverages. Under reaction conditions, the $\alpha-\mathrm{Fe}_{2} \mathrm{O}_{3}(0001)$ surface is estimated to be partially covered and actually it is catalytically active. The $\mathrm{Fe}_{3} \mathrm{O}_{4}(111)$ surface, however, is estimated to be fully covered so that not only site blocking by the product molecule St but also the unfavourable tilted configuration of the educt EB may be responsible for the missing activity.

The interaction of $\mathrm{EB}$ and St with the $\mathrm{FeO}(111)$ surface is weak and of the physisorption type. High tilt angles of about $40^{\circ}$ are found even at low coverage. Obviously the adsorbate-adsorbate interaction dominates always over the adsorbatesubstrate interaction and causes growth in form of two-dimensional islands.

\section{Acknowledgement}

This project was funded by the Deutsche Forschungsgemeinschaft (Contract No. WE 1372/5-2 and Do-561/1-3). The authors thank M. Mast and W. Braun at the Berlin synchrotron facility BESSY I and M. Swoboda from the Fritz-Haber Institut, Berlin, for the technical support. 


\section{References}

[1] J.W. Geus, Appl. Catal. , 1986, 25, 313.

[2] M. Muhler, J. Schütze, M. Wesemann, T. Rayment, A. Dent, R. Schlögl, and G. Ertl, J. Catal. , $1990,126,339$.

[3] M. Muhler, R. Schlögl and G. Ertl, J. Catal. , 1992, 138, 413.

[4] E.H. Lee, Catal. Rev. , 1973, 8, 285.

[5] K. Coulter, D.W. Goodman, and R.G. More, Catal. Lett. , 1995, 31, 1.

[6] T. Hirano, Appl. Catal. , 1986, 26, 65.

[7] T. Hirano, Appl. Catal. , 1986, 28, 119

[8] W. Weiss, D. Zscherpel, and R. Schlögl, Catal. Lett. , 1998, 52, 215.

[9] D. Zscherpel, W. Weiss, and R. Schlögl, Surf. Sci. , 1997, 382, 326.

[10] C. Kuhrs and W. Weiss, Stud. Surf. Sci. Catal. , 2000, 130, 2225.

[11] W. Weiss, Surf. Sci. , 1997, 377, 943.

[12] W. Weiss and M. Ritter, Phys. Rev., 1999, B59, 5201.

[13] Th. Schedel-Niedrig, W. Weiss, and R. Schlögl, Phys. Rev. , 1995, B52, 17449.

[14] M. Ritter, W. Ranke, and W. Weiss, Phys. Rev. , 1998, B57, 7240.

[15] M. Ritter and W. Weiss, Surf. Sci. , 1999, 432, 81.

[16] Sh.K. Shaikhutdinov and W. Weiss, Surf. Sci. , 1999, 432, L627.

[17] W. Ranke, M. Ritter, and W. Weiss, Phys. Rev. , 1999, B60, 1527.

[18] W. Ranke and W. Weiss, Surf. Sci. , 1998, 414, 238.

[19] D. Zscherpel, W. Ranke, W. Weiss, and R. Schlögl, J. Chem. Phys. , 1998, 108, 9506.

[20] Y. Joseph, C. Kuhrs, W. Ranke, M. Ritter, and W. Weiss, Chem. Phys. Lett. , 1999, 314, 195.

[21] Y. Joseph, W. Ranke, and W. Weiss, J. Chem. Phys. , 2000, B104, 3224.

[22] Sh. K. Shaikhutdinov, Y. Joseph, C. Kuhrs, W. Ranke, and W. Weiss, Farad. Disc., 1999, $114,363$.

[23] C. Kuhrs, Y. Arita, W. Weiss, W. Ranke, and R. Schlögl, Topics in Catalysis, 2000, in print.

[24] S. Bernstorff, W. Braun, M. Mast, W. Peatmann, and T. Schroeter, Rev. Sci. Instrum. , 1989, 60, 2097.

[25] F. Nakao, Vacuum, 1975, 25, 431.

[26] J. Stöhr, NEXAFS Spectroscopy, Springer Series in Surface Science, Springer Verlag, Berlin, Vol. $25,1996$.

[27] K. Weiss, S. Gebert, M. Wühn, H. Wadepohl, and Ch. Wöll, J. Vac. Sci. Technol. , 1998, A16, 1017.

[28] K. Weiss, J. Weckesser, and Ch. Wöll, J. Mol. Struct. , 1996, 458, 143.

[29] J.L. Solomon, R.J. Madix, and J. Stöhr, Surf. Sci. , 1991, 255, 12

[30] M. Wühn, Y. Joseph, P. S. Bagus, A. Niklewski, R. Puettner, S. Reiß, W. Weiss, M. Martins, G. Kaindl, and Ch. Wöll, J. Phys. Chem. B, 2000, in print.

[31] G. Polzonetti, V. Carravetta, M. V. Russo, G. Contini, P. Parent, and C. Lafon, J. Electron Spectrosc. Related Phenomen. , 1999, 98-99, 175.

[32] I. Kopinarov, A. Lippitz, J. F. Friedrich, W. E. S. Unger, and Ch. Wöll, Polymer, 1998, 39, 3001.

[33] R. Puettner, (Freie Universität, Berlin) private communication.

[34] C. Elschenboich, A. Salzer, Organometallchemie, Teubener Sudienbücher, Stuttgart, Germany, 1993.

[35] C. Mainka, P. S. Bagus, A. Schertel, T. Strunskus, M. Grunze, and Ch. Wöll, Surf. Sci. , 1995, 341, 1055.

[36] D. Schröder and H. Schwarz, Angw. Chem. ,1995, 107, 2126.

[37] H. Becker, Diploma Thesis (Technische Universität, Berlin), 1992 
Tab. 1: $\quad$ Energetic positions and assignments of the NEXAFS resonances observed in figs. 3-6.

\begin{tabular}{|c|c|c|}
\hline Resonance & $\begin{array}{c}\text { Energetic position } \\
(\mathrm{eV})\end{array}$ & Assignment \\
\hline $\begin{array}{c}\mathrm{A}^{\prime} \text { (only } \\
\text { styrene) }\end{array}$ & 284.1 & $\pi^{*}$, vinyl group \\
\hline A & 285.0 & $\pi^{*}$, ring (benzene: $\left.\mathrm{C} 1 \mathrm{~s} \rightarrow \mathrm{e}_{2 \mathrm{u}}\right)$ \\
\hline \multirow{2}{*}{ B } & 286.9 & Rydberg, side chain (octane) \\
\cline { 2 - 3 } & 287.6 & Rydberg, ring (benzene) \\
\cline { 2 - 3 } & 288.0 & Rydberg, side chain (octane) \\
\hline \multirow{2}{*}{ C } & 288.9 & $\pi^{*}$, ring (benzene: $\left.\mathrm{C} 1 \mathrm{~s} \rightarrow \mathrm{b}_{2 \mathrm{~g}}\right)$ \\
\hline \multirow{2}{*}{$\mathrm{D}$} & 293.1 & $\sigma^{*}$, side chain $($ octane) \\
\hline \multirow{2}{*}{ E } & 293.3 & $\sigma^{*}$, ring (benzene: $\left.\mathrm{C} 1 \mathrm{~s} \rightarrow \mathrm{e}_{1 \mathrm{u}}\right)$ \\
\hline & 300.2 & $\sigma^{*}$, ring (benzene: $\left.\mathrm{C} 1 \mathrm{~s} \rightarrow \mathrm{e}_{1 \mathrm{u}}+\mathrm{a}_{2 \mathrm{~g}}\right)$ \\
\hline & 301.0 & $\sigma^{*}$, side chain $($ octane) \\
\hline
\end{tabular}

Table 1 


\section{Figures}
$\mathrm{FeO}(111)$
$\mathrm{Fe}_{3} \mathrm{O}_{4}(111)$
$\alpha-\mathrm{Fe}_{2} \mathrm{O}_{3}(0001)$
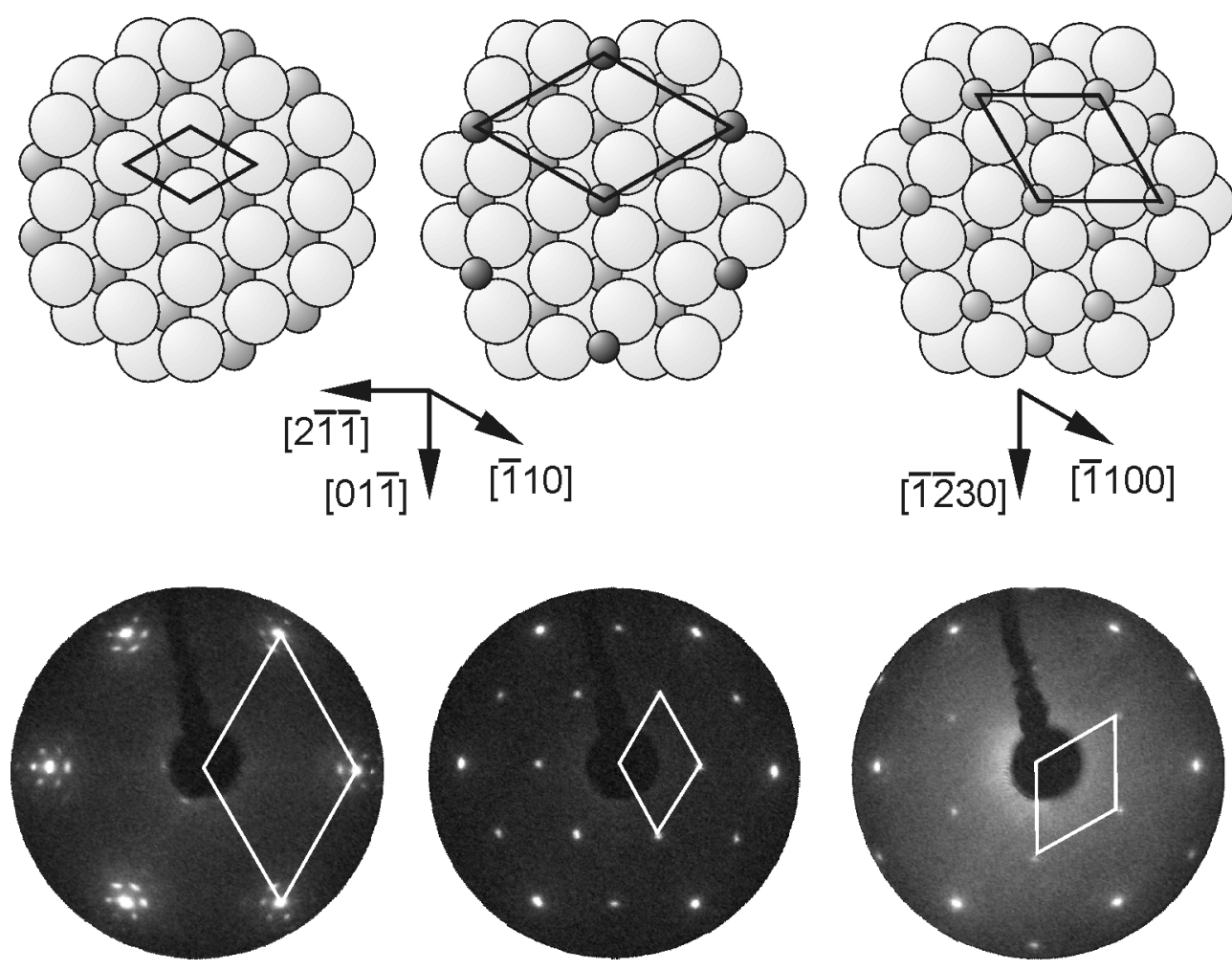

Fig.1: Top views (schematic) and observed LEED patterns of the epitaxial films with $\mathrm{FeO}(111), \mathrm{Fe}_{3} \mathrm{O}_{4}(111)$ and $\alpha$ $\mathrm{Fe}_{2} \mathrm{O}_{3}(0001)$ structure prepared on $\mathrm{Pt}(111)$. Large balls mark oxygen, small balls iron atoms. The surface unit cells are marked. The $\mathrm{FeO}(111)$ film is only one Fe-O bilayer thick. The mismatch with the Pt substrate leads to the satellite pattern in LEED caused by multiple scattering.
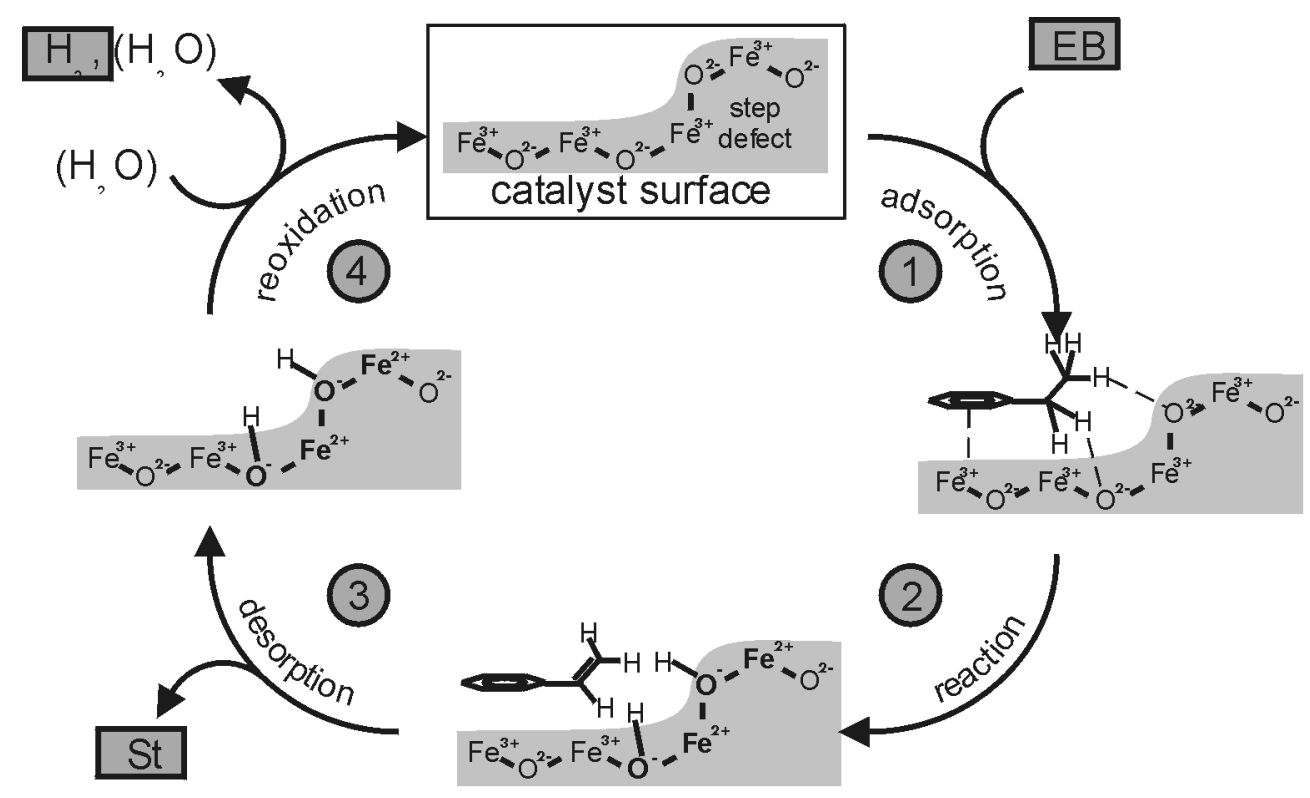

Fig. 2: Reaction mechanism proposed for the ethylbenzene dehydrogenation over iron oxides taken from ref.[23] 


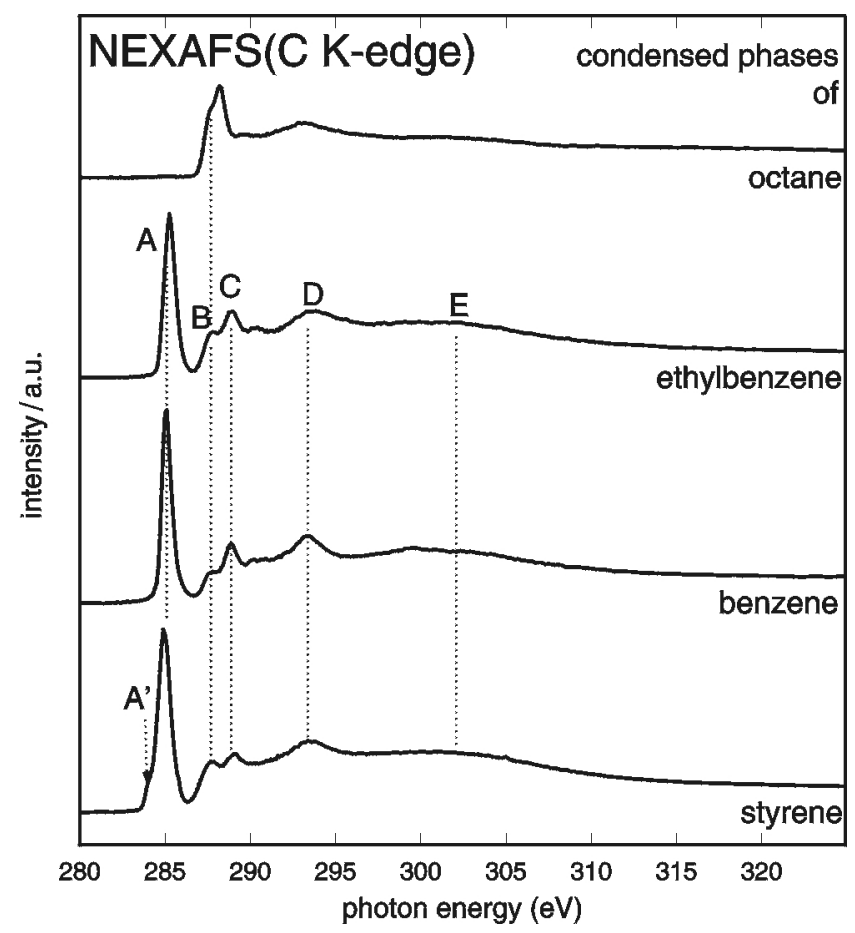

Fig. 3: Comparison of the carbon K-edge NEXAFS spectra of the condensed phases of styrene, benzene, ethylbenzene and octane. The assignment of the resonances A' and A-E is given in table 1.

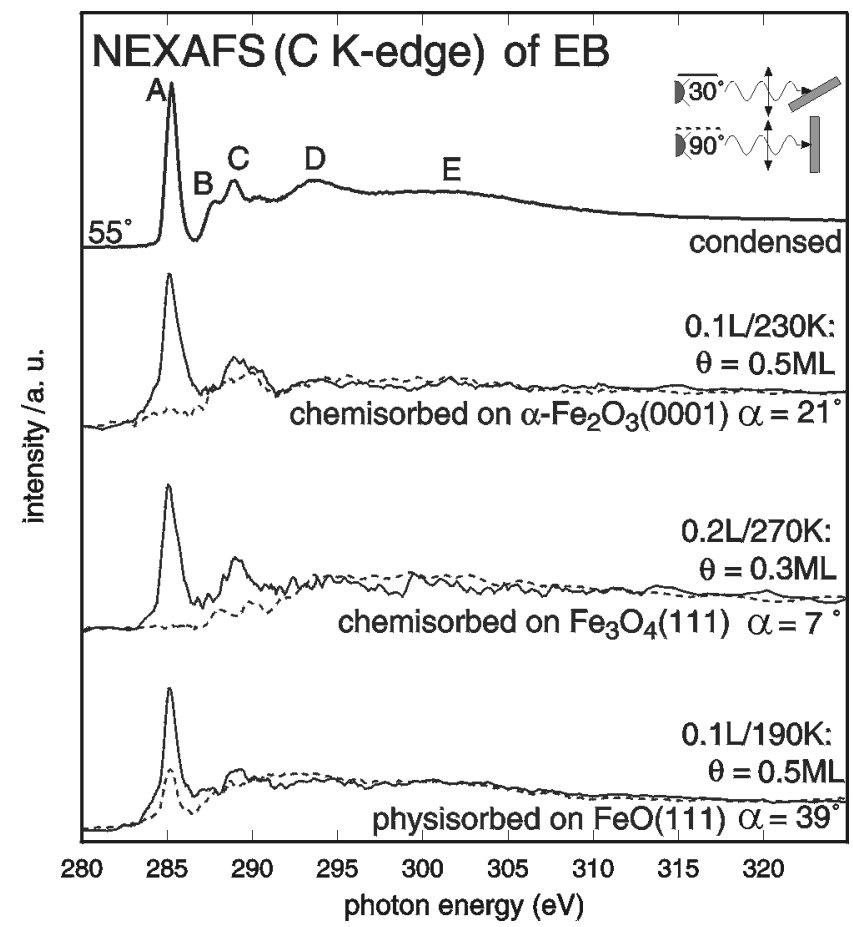

Fig. 4: Carbon K-edge NEXAFS spectra of ethylbenzene layers on the different iron oxides in the submonolayer regime. Full lines: grazing incidence $\left(30^{\circ}\right)$; dashed: normal incidence $\left(90^{\circ}\right)$. The exposure conditions (doses and temperatures), the resulting coverages $(\theta)$ and the calculated tilt angles between the molecular plane and the surfaces $(\alpha)$ are indicated. 


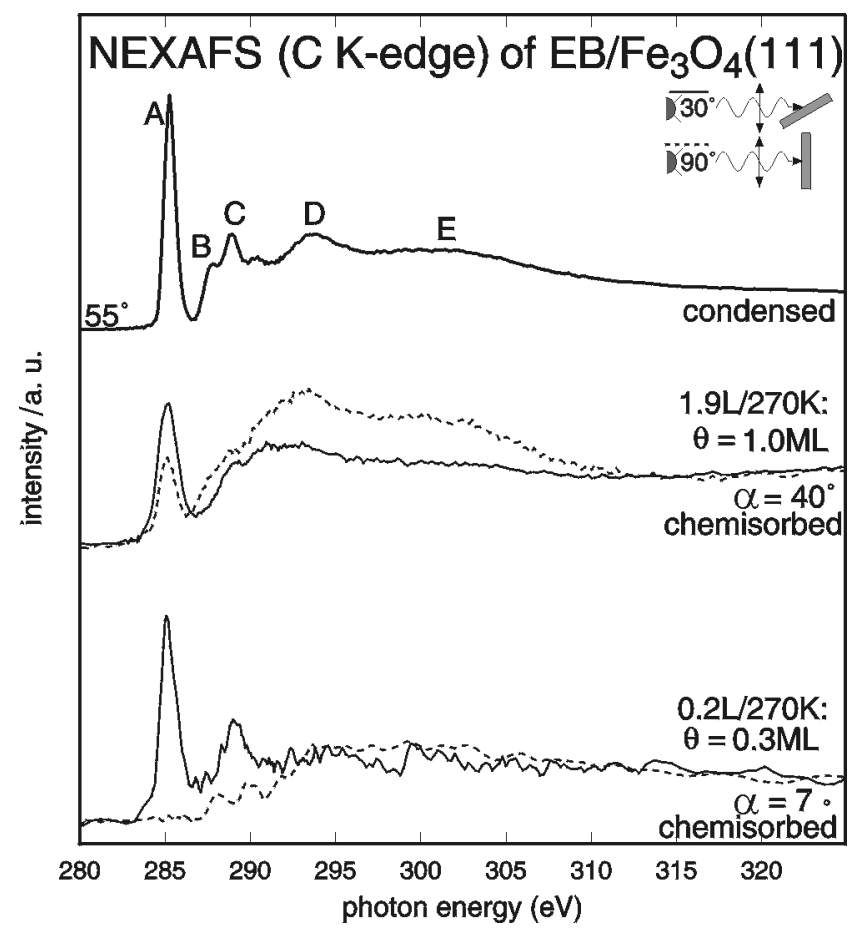

Fig. 5: Coverage dependence of the carbon K-edge NEXAFS spectra for EB chemisorbed on $\mathrm{Fe}_{3} \mathrm{O}_{4}(111)$. Full lines: grazing incidence $\left(30^{\circ}\right)$; dashed: normal incidence $\left(90^{\circ}\right)$. The exposure conditions (doses and temperatures), the resulting coverages $(\theta)$ and the calculated tilt angles between the molecular plane and the surface $(\alpha)$ are indicated.

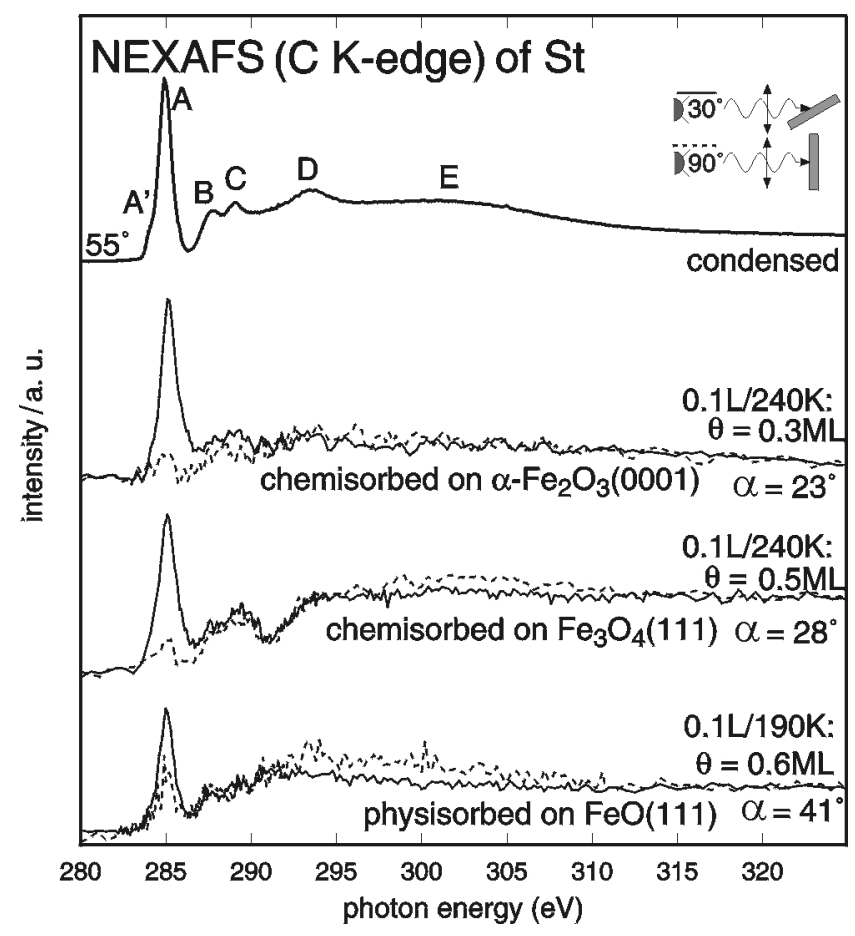

Fig. 6: Carbon K-edge NEXAFS spectra of styrene layers on the different iron oxides in the submonolayer regime. Full lines: grazing incidence $\left(30^{\circ}\right)$; dashed: normal incidence $\left(90^{\circ}\right)$. The exposure conditions (doses and temperatures), the resulting coverages $(\theta)$ and the calculated tilt angles $(\alpha)$ between the molecular plane and the respective surfaces are indicated. 
a)

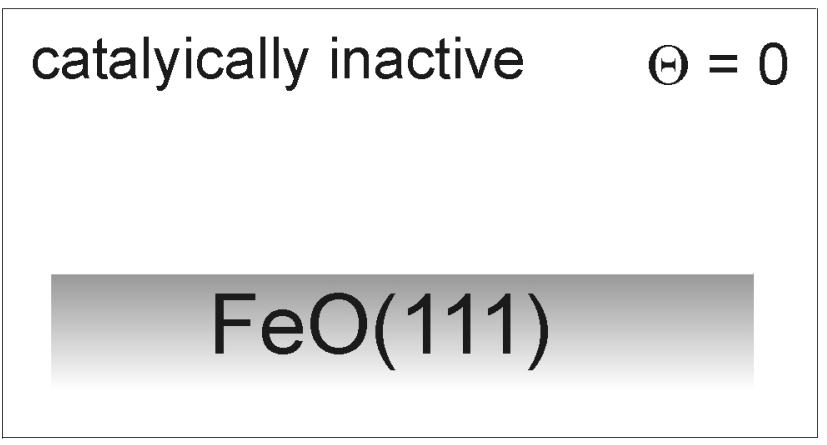

b)

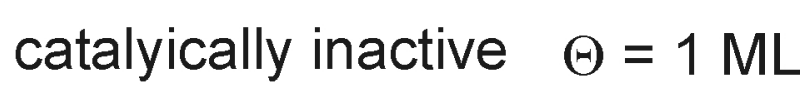

c)

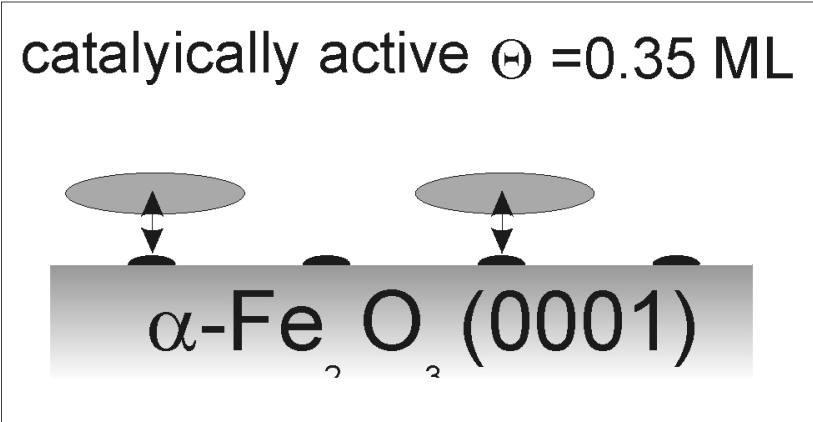

Fig. 7: Illustration of the adsorption geometry and the dominating interactions for EB or St on (a) FeO(111), (b) $\mathrm{Fe}_{3} \mathrm{O}_{4}(111)$, and (c) $\mathrm{Fe}_{2} \mathrm{O}_{3}(0001)$ at coverages estimated for reaction conditions[22] $(\mathrm{T}=870 \mathrm{~K}, \mathrm{p}=1 \mathrm{~atm})$. Only for the catalytically active $\mathrm{Fe}_{2} \mathrm{O}_{3}$ system a $\eta^{6}$ configuration is expected. 